\title{
Bloodstream Infections in Hospitalized Patients with COVID-19: A Systematic Review and Meta-Analysis
}

\author{
Mariachiara Ippolito ${ }^{1} \mathbb{D}$, Barbara Simone $^{1}$, Carlotta Filisina $^{1}$, Francesca Romana Catalanotto ${ }^{1}$, \\ Giulia Catalisano ${ }^{1}\left(\mathbb{D}\right.$, Claudia Marino ${ }^{1}$, Giovanni Misseri ${ }^{2} \mathbb{D}$, Antonino Giarratano ${ }^{1,3}$ and \\ Andrea Cortegiani 1,3,*(D)
}

Citation: Ippolito, M.; Simone, B.; Filisina, C.; Catalanotto, F.R.;

Catalisano, G.; Marino, C.; Misseri, G.; Giarratano, A.; Cortegiani, A.

Bloodstream Infections in

Hospitalized Patients with COVID-19:

A Systematic Review and

Meta-Analysis. Microorganisms 2021,

9, 2016. https://doi.org/10.3390/

microorganisms 9102016

Academic Editor:

Sofia Costa-de-Oliveira

Received: 8 September 2021

Accepted: 22 September 2021

Published: 23 September 2021

Publisher's Note: MDPI stays neutral with regard to jurisdictional claims in published maps and institutional affiliations.

Copyright: (c) 2021 by the authors. Licensee MDPI, Basel, Switzerland. This article is an open access article distributed under the terms and conditions of the Creative Commons Attribution (CC BY) license (https:// creativecommons.org/licenses/by/ $4.0 /)$.
1 Department of Surgical, Oncological and Oral Science (Di.Chir.On.S.), University of Palermo, 90127 Palermo, Italy; mariachiara.ippolito@community.unipa.it (M.I.); barbara.simone1993@gmail.com (B.S.); carlottafilisina@gmail.com (C.F.); francesca.catalanott@libero.it (F.R.C.); giuliacatalisano@gmail.com (G.C.); dott.ssacmarino@gmail.com (C.M.); antonino.giarratano@unipa.it (A.G.)

2 Fondazione Giglio, 90015 Cefalù, Italy; giovannimisseri1987@gmail.com

3 Department of Anaesthesia, Intensive Care and Emergency, Policlinico Paolo Giaccone, 90127 Palermo, Italy

* Correspondence: andrea.cortegiani@unipa.it; Tel.: +39-091-655-2730

\begin{abstract}
Background: Little is known about the occurrence of bloodstream infections in hospitalized patients with COVID-19 and the related clinical consequences. The aim of this systematic review and meta-analysis was to estimate the pooled occurrence of BSIs among hospitalized patients with COVID-19 and mortality of this patient population. Methods: A systematic search was performed on PubMed, EMBASE, and Web of Science from inception to 19 April 2021. The primary outcome was the occurrence of BSIs among hospitalized patients with COVID-19. The secondary outcome was mortality at the longest available follow-up. Results: Forty-six studies met the inclusion criteria, with a total of 42,694 patients evaluated. The estimated occurrence of BSIs was 7.3\% (95\% CI 4.7-1.1\%) among hospitalized patients with COVID-19, with a mortality rate of $41 \%$ (95\% CI 30\%-52.8\%). The subgroup analysis conducted on patients admitted to ICU provided an estimated occurrence of $29.6 \%$ (95\% CI 21.7\%-38.8\%). A higher occurrence of BSI was observed in patients with COVID-19, in comparison with patients without COVID-19 (OR 2.77; 95\% CI 1.53-5.02; $p<0.001$ ). Conclusions: Our analysis estimated the occurrence of BSIs among hospitalized patients with COVID-19 at around $7 \%$. A four-times higher occurrence was estimated among patients admitted to ICU.
\end{abstract}

Keywords: bloodstream infections; COVID-19; review

\section{Introduction}

Bloodstream infections (BSIs) are frequently causes of infection, sepsis, or septic shock in hospitalized [1] and critically ill patients [2]. Whether community or hospital acquired, BSIs may complicate patients' hospital stay and have been associated with negative outcomes [1]. The COVID-19 pandemic has caused the hospitalization of a substantial number of patients with acute respiratory failure. Previous reports have described the occurrence of BSIs in cohorts of patients with other viral pneumonia (e.g., influenza) [3,4]. The clinical features of SARS-CoV-2 infection, the use of immunomodulatory drugs, and the high rate of admission to ICU may pose patients with COVID-19 at a high risk of developing superinfections [5], such as ventilator-associated pneumonia and BSIs [6]. To date, fragmented data are available on the occurrence of BSIs in populations of hospitalized patients with COVID-19, and little is known about how BSIs may influence the outcome of these patients.

The aim of this systematic review and meta-analysis is to estimate the pooled occurrence of BSIs among hospitalized patients with COVID-19 and mortality of this patient population. 


\section{Materials and Methods}

The protocol of this systematic review and meta-analysis was prospectively registered in the Open Science Framework (https://osf.io/ys8kd). For the purpose of this systematic review and meta-analysis, a systematic search was performed on PubMed, EMBASE, and Web of Science from inception to 19 April 2021. The search strategy included keywords as exact phrases and subject headings, according to database syntaxes, and is available as Supplementary Material. The reference list of relevant articles was also screened (i.e., the snowballing method). Full literature search records were then screened independently and by four authors in blinded pairs (MI, BS, CF, FRC) to identify all relevant records from titles and abstracts. Studies selected as relevant were then evaluated from the full text and included if two reviewers independently agreed on their eligibility. Nonrandomized studies, both prospective and retrospective, were considered eligible when specifically addressing the occurrence of bloodstream infections (BSIs) in adult and hospitalized patients with COVID-19, defined as the proportion of patients who developed at least one BSI during the study period, which divided the cohort of the study. The occurrence rate of BSI was the primary outcome of the study. The secondary outcome was mortality of patients with BSI and COVID-19 at the longest available follow-up. Case-control studies with a predefined or fixed proportion of enrollment between infected and non-infected were excluded, due to their design, as they were not able to provide a reliable estimate of the occurrence of BSI. Studies presenting data on only one family or species of microorganism were excluded, as they were not able to provide a reliable estimate of the overall occurrence of BSI. Studies including less than 10 patients (i.e., case series), case reports, abstracts, not peer-reviewed articles, and articles not in the English language were excluded. The Preferred Reporting Items for Systematic reviews and Meta-Analyses (PRISMA) [7] checklist is provided in Supplementary Material. Data collection was performed in duplicate and using an electronic standardized data extraction form. Discrepancies at any stage are resolved by discussion. When the disagreement was due to a difference in interpretation, arbitration was conducted by another author (GC or $\mathrm{CM}$ ). The corresponding authors of the included studies were contacted to obtain additional information regarding eligibility or data presentation, if needed, by two authors (MI and AC).

\subsection{Qualitative Analysis}

Qualitative analysis of included studies was performed using the Methodological Index for Non-Randomized studies (MINORS) [8], due to its ability to be used for the assessment of single arm studies, independently and in duplicate by two authors (GC, MI). Disagreements over the assessment were resolved by a third author (AC). The items were scored as 0 (not reported), 1 (reported but inadequate), or 2 (reported and adequate). The global ideal score was 16 for non-comparative studies and 24 for comparative studies.

\subsection{Statistical Analysis}

Meta-analysis was performed in the case of two or more included studies reporting data on the outcomes of interest. The summary estimates were derived from logit transformation of individual study proportions of the outcomes and presented along with the corresponding 95\% confidence interval (CI), calculated using random-effect meta-analysis. The I-squared $\left(\mathrm{I}^{2}\right)$ statistical model was used to describe the percentage of variation across the included studies due to heterogeneity. Prespecified subgroup analyses were performed on the basis of the setting (e.g., intensive care unit, non-intensive care wards) and the number of centers per study (e.g., multicenter, single center). We also performed a sensitivity analysis, including studies comparing the outcomes of patients with COVID-19 to those of patients without COVID-19. A post-hoc subgroup analysis was performed on studies including only hospital-acquired BSI. All the analyses were performed by MI with inputs from AC, using Open Meta-Analyst 8 [9]. 


\section{Results}

\subsection{Characteristics of Included Studies and Patients}

A total of 1172 records were retrieved. The full search output is available as Supplementary Material. After the screening of the records, a total of 46 studies were included in this systematic review and meta-analysis [6,10-54]. The included studies provided data on a total of 42,694 patients with COVID-19. The inclusion/exclusion process is presented as a PRISMA flow diagram, as shown in Figure 1.

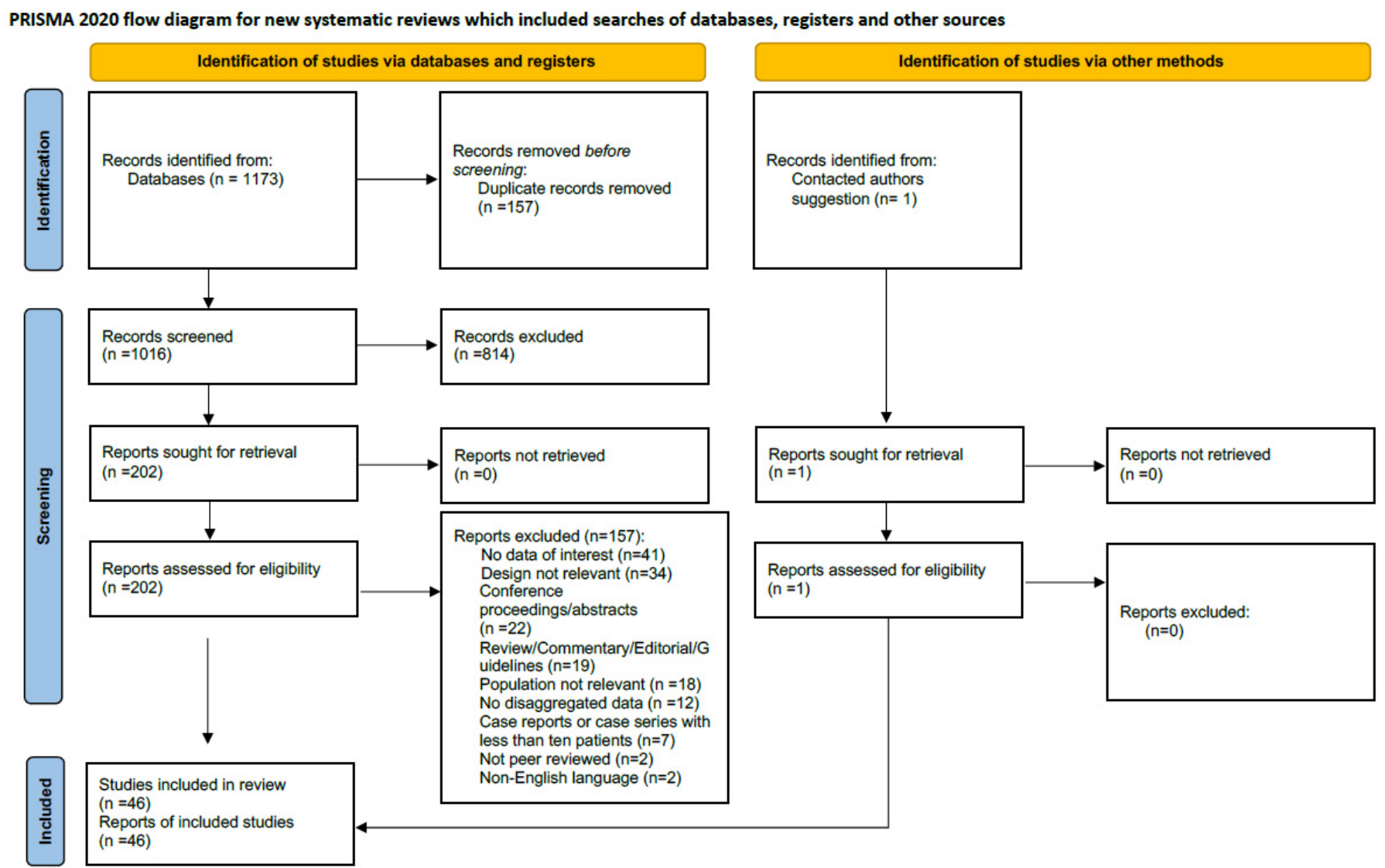

Figure 1. PRISMA 2020 flow diagram.

The characteristics of the included studies are presented in Table 1. Sixteen studies were multicentric and 30 were conducted in a single center. Twenty-nine studies were conducted in EU, 10 in USA, four in China, and three in other countries. The included patients had an age ranging from 32 to 70 years, with a percentage of male gender in the cohorts ranging from $48 \%$ to $94 \%$. All the studies were single-arm studies, except 11 also presenting data on patients without COVID-19 as a comparator. Details on isolates and source of the infection are provided in Table S2, Supplementary Material. Data on causative microorganisms showed that the infections were mainly bacterial and rarely fungal BSIs, with Gram positive species prevalent in many studies. The qualitative assessment per study, according to MINORS, is provided in Tables S3 and S4, Supplementary Material. Only two $[52,55]$ of the studies reported protocol registration and none reported information on sample calculation. Among the 11 studies with a comparison group, all except two had historical comparison groups $[27,35]$. Furthermore, 8 out of 11 studies reported only unadjusted statistical analysis $[10,12,18,20,22,27,28,44]$. These were the most frequently downgraded domains. 
Table 1. Characteristics of the included studies. The table shows the main characteristics of the included studies, as reported by the authors. BSI, bloodstream infection; CRBI, catheter-related bloodstream infection; ECMO, extracorporeal membrane oxygenation; ICU, intensive care unit; NA, not available; RT-PCR, real-time polymerase chain reaction.

\begin{tabular}{|c|c|c|c|c|c|}
\hline $\begin{array}{l}\text { Authors } \\
\text { (Year) }\end{array}$ & $\begin{array}{l}\text { Design of the Study } \\
\text { (Country) }\end{array}$ & Setting & Population & $\begin{array}{l}\text { Comparison Group } \\
\text { (non COVID-19): }\end{array}$ & Definitions \\
\hline $\begin{array}{l}\text { Adler et al. } \\
(2020) \text { [38] }\end{array}$ & $\begin{array}{l}\text { Single center } \\
\text { retrospective } \\
\text { observational study } \\
\text { (UK) }\end{array}$ & $\begin{array}{l}\text { Both ICU } \\
\text { and non-ICU }\end{array}$ & $\begin{array}{l}195 \text { hospitalized } \\
\text { patients with } \\
\text { COVID-19 (RT-PCR); } \\
\text { Age } 69 \text { y. [59-81]; } \\
\text { Male } 60.5 \%\end{array}$ & NA & $\begin{array}{l}\text { Samples unequivocally consistent } \\
\text { with contamination were considered } \\
\text { negative. Results recorded until } 7 \\
\text { days from the positive COVID-19 to } \\
\text { exclude hospital-acquired infections }\end{array}$ \\
\hline $\begin{array}{l}\text { Akagi et al. } \\
(2021) \text { [45] }\end{array}$ & $\begin{array}{l}\text { Single center } \\
\text { retrospective, } \\
\text { case-control study } \\
\text { (USA) }\end{array}$ & Non-ICU & $\begin{array}{l}565 \text { hospitalized } \\
\text { patients with } \\
\text { COVID-19; } \\
\text { Age } 64.5 \text { y. } \pm 16.4 ; \\
\text { Male } 57.1 \%\end{array}$ & NA & $\begin{array}{l}\text { Community onset bloodstream } \\
\text { infection } \\
\text { Positive blood culture with a known } \\
\text { pathogen in one or more blood } \\
\text { cultures or the same commensal } \\
\text { organism in two or more blood } \\
\text { cultures drawn within } 48 \text { h of } \\
\text { hospitalization }\end{array}$ \\
\hline $\begin{array}{l}\text { Bardi et al. } \\
(2021)[14]\end{array}$ & $\begin{array}{l}\text { Single center } \\
\text { retrospective } \\
\text { observational study } \\
\text { (Spain) }\end{array}$ & ICU & $\begin{array}{l}140 \text { patients with } \\
\text { severe COVID-19 } \\
\text { (RT-PCR), admitted } \\
\text { to ICU } \\
\text { Age } 61 \text { y. [57-67], } \\
\text { Male } 77 \%\end{array}$ & NA & $\begin{array}{l}\text { All infections were defined according } \\
\text { to the Centers for Disease Control and } \\
\text { Prevention criteria and the Spanish } \\
\text { Society of Infectious Diseases and } \\
\text { Clinical Microbiology }\end{array}$ \\
\hline $\begin{array}{l}\text { Barry et al. } \\
\text { (2021) [49] }\end{array}$ & $\begin{array}{l}\text { Single center case } \\
\text { series } \\
\text { (Saudi Arabia) }\end{array}$ & $\begin{array}{l}\text { Both ICU } \\
\text { and non-ICU }\end{array}$ & $\begin{array}{l}605 \text { hospitalized } \\
\text { patients with } \\
\text { COVID-19 } \\
\text { Age } 75 \%<65 y \\
\text { Male } 61 \%\end{array}$ & NA & NA \\
\hline $\begin{array}{l}\text { Baskaran } \\
\text { et al. }(2021) \\
{[33]}\end{array}$ & $\begin{array}{l}\text { Multicenter } \\
\text { retrospective } \\
\text { observational study } \\
\text { (UK) }\end{array}$ & ICU & $\begin{array}{l}254 \text { patients with } \\
\text { COVID-19 (RT-PCR) } \\
\text { admitted to ICU, } \\
\text { Age } 59 \text { y. [49-69], } \\
\text { Male } 64.6 \%\end{array}$ & NA & $\begin{array}{l}\text { Culture results were excluded if they } \\
\text { were considered to represent } \\
\text { contamination or colonisation }\end{array}$ \\
\hline $\begin{array}{l}\text { Bayo et al. } \\
(2020) \text { [28] }\end{array}$ & $\begin{array}{l}\text { Single center } \\
\text { retrospective cohort } \\
\text { study (Spain) }\end{array}$ & $\begin{array}{l}\text { Both ICU } \\
\text { and non-ICU }\end{array}$ & $\begin{array}{l}2923 \text { hospitalized } \\
\text { patients with } \\
\text { COVID-19 (RT-PCR), } \\
\text { Age } 64.5 \text { [NA] } \\
\text { Male } 86 \%\end{array}$ & $\begin{array}{l}29,314 \text { hospitalized } \\
\text { patients, } \\
\text { Age } 65.9 \text { [NA] } \\
\text { Male } 67 \%\end{array}$ & $\begin{array}{l}\text { Blood culture contamination was } \\
\text { defined as the presence of one or more } \\
\text { of the following organisms found in } \\
\text { only one blood culture set and only } \\
\text { one of a series of two or three blood } \\
\text { culture sets: coagulase-negative } \\
\text { staphylococci, Micrococcus spp., } \\
\text { viridans group streptococci, } \\
\text { Propionibacterium acnes, } \\
\text { Corynebacterium spp., and Bacillus } \\
\text { spp. }\end{array}$ \\
\hline $\begin{array}{l}\text { Blazoski et al. } \\
\text { (2021) [39] }\end{array}$ & $\begin{array}{l}\text { Single center } \\
\text { retrospective } \\
\text { observational study } \\
\text { (USA) }\end{array}$ & $\mathrm{ICU}$ & $\begin{array}{l}20 \text { patients with } \\
\text { COVID-19 admitted } \\
\text { to ICU and treated } \\
\text { with ECMO; } \\
\text { Age } 54 \pm 8.7 \\
\text { Male } 60 \%\end{array}$ & NA & NA \\
\hline $\begin{array}{l}\text { Bonazzetti } \\
\text { et al. }(2020) \\
{[36]}\end{array}$ & $\begin{array}{l}\text { Single center } \\
\text { retrospective } \\
\text { observational study } \\
\text { (Italy) }\end{array}$ & $\mathrm{ICU}$ & $\begin{array}{l}89 \text { patients with } \\
\text { COVID-19 admitted } \\
\text { to ICU, } \\
\text { Age } 61.5 \mathrm{y} \text {. } \\
\text { [53.1-68.7]; } \\
\text { Male } 77.5 \%\end{array}$ & NA & $\begin{array}{l}\text { BSIs were defined using the Center for } \\
\text { Disease and Control criteria. BSI due } \\
\text { to organisms usually associated with } \\
\text { contamination had to be confirmed in } \\
\text { two sets of blood cultures. } \\
\text { ICU-acquired BSI if diagnosed greater } \\
\text { than or equal to } 48 \mathrm{~h} \text { after ICU } \\
\text { admission }\end{array}$ \\
\hline $\begin{array}{l}\text { Buehler et al. } \\
\text { (2021) [37] }\end{array}$ & $\begin{array}{l}\text { Single center } \\
\text { prospective } \\
\text { observational study } \\
\text { (Switzerland) }\end{array}$ & ICU & $\begin{array}{l}45 \text { patients with } \\
\text { COVID-19 (RT-PCR) } \\
\text { admitted to ICU, } \\
\text { Age } 60 \text { y. [54-69], } \\
\text { Male } 77.8 \%\end{array}$ & NA & NA \\
\hline
\end{tabular}


Table 1. Cont.

\begin{tabular}{|c|c|c|c|c|c|}
\hline $\begin{array}{l}\text { Authors } \\
\text { (Year) }\end{array}$ & $\begin{array}{l}\text { Design of the Study } \\
\text { (Country) }\end{array}$ & Setting & Population & $\begin{array}{l}\text { Comparison Group } \\
\text { (non COVID-19): }\end{array}$ & Definitions \\
\hline $\begin{array}{l}\text { Buetti et al. } \\
\text { (2021) [6] }\end{array}$ & $\begin{array}{l}\text { Multicenter } \\
\text { prospective } \\
\text { observational study } \\
\text { (France) }\end{array}$ & $\mathrm{ICU}$ & $\begin{array}{l}235 \text { patients with } \\
\text { COVID-19, admitted } \\
\text { to ICU, } \\
\text { Age } 59.8 \text { y. } \pm 12.7 \\
\text { Male } 80 \%\end{array}$ & $\begin{array}{l}\text { Historical cohort of } \\
235 \text { patients with } \\
\text { ARDS, admitted to } \\
\text { ICU } \\
\text { Age } 59.8 \text { y. } \pm 13.8 \\
\text { Male } 80 \%\end{array}$ & $\begin{array}{l}\text { ICU-BSI } \\
\text { infection onset occurring }>48 \mathrm{~h} \text { after } \\
\text { ICU admission. Typical skin } \\
\text { contaminants were included if } \geq 2 \\
\text { blood cultures showed the same } \\
\text { phenotype within a } 48 \text {-h period or } \geq 1 \\
\text { blood culture positive for clinical } \\
\text { sepsis, no other infectious process, } \\
\text { and antibacterial agent treatment } \\
\text { initiated by the attending physician } \\
\text { Secondary BSI } \\
\text { same microorganism in one blood } \\
\text { culture and in the suspected source of } \\
\text { infection. All catheter-related BSI } \\
\text { (CRBSI) were documented by } \\
\text { quantitative tip culture }\end{array}$ \\
\hline $\begin{array}{l}\text { Cataldo et al. } \\
(2020)[12]\end{array}$ & $\begin{array}{l}\text { Single center } \\
\text { retrospective cohort } \\
\text { study } \\
\text { (Italy) }\end{array}$ & ICU & $\begin{array}{l}57 \text { patients with } \\
\text { COVID-19 admitted } \\
\text { to ICU, Age } 62 \mathrm{y} . \pm \\
13, \text { Male } 72 \%\end{array}$ & $\begin{array}{l}\text { Historical cohort of } \\
75 \text { patients admitted } \\
\text { to ICU }\end{array}$ & NA \\
\hline $\begin{array}{l}\text { Cates et al. } \\
(2020)[16]\end{array}$ & $\begin{array}{l}\text { Multicenter } \\
\text { retrospective } \\
\text { observational study } \\
\text { (USA) }\end{array}$ & $\begin{array}{l}\text { Both ICU } \\
\text { and non-ICU }\end{array}$ & $\begin{array}{l}3948 \text { hospitalized } \\
\text { patients with } \\
\text { COVID-19 (RT-PCR), } \\
\text { Age } 70 \text { y. [61-77], } \\
\text { Male } 94 \%\end{array}$ & $\begin{array}{l}5453 \text { hospitalized } \\
\text { patients with } \\
\text { influenza A or B } \\
\text { (RT-PCR or other), } \\
\text { Age } 69 \text { [61-75], } \\
\text { Male } 93.8 \%\end{array}$ & ICD-10-CM codes \\
\hline
\end{tabular}

BSI

non-skin flora commensal on one or more blood culture to define a bloodstream infection as that caused by a common skin colonizer. Two or more blood cultures drawn from different sites were required plus a clinical evaluation. Co-infections if present at the time of admission (initial $48 \mathrm{~h}$ ), secondary infections if emerged during the course of hospitalization

\begin{tabular}{|c|c|c|c|c|c|}
\hline $\begin{array}{l}\text { Cheng et al. } \\
(2020) \text { [47] }\end{array}$ & $\begin{array}{l}\text { Single center } \\
\text { retrospective } \\
\text { observational study } \\
\text { (China) }\end{array}$ & NA & $\begin{array}{l}212 \text { hospitalized } \\
\text { patients with } \\
\text { COVID-19; } \\
\text { Age } 53.1 \text { y. } \pm 16.6 ; \\
\text { Male } 60 \%\end{array}$ & NA & $\begin{array}{l}\text { According to the diagnostic standard } \\
\text { of nosocomial infection formulated by } \\
\text { the China's Ministry of Health in } 2001\end{array}$ \\
\hline $\begin{array}{l}\text { Contou et al. } \\
(2020)[53]\end{array}$ & $\begin{array}{l}\text { Single center } \\
\text { retrospective } \\
\text { observational study } \\
\text { (France) }\end{array}$ & ICU & $\begin{array}{l}92 \text { patients with } \\
\text { COVID-19 (RT-PCR) } \\
\text { admitted to ICU, } \\
\text { Age } 61 \text { y. [55-70], } \\
\text { Male } 79 \%\end{array}$ & NA & $\begin{array}{l}\text { A patient was considered as } \\
\text { co-infected when at least one of the } \\
\text { performed microbiological } \\
\text { investigations isolated a pathogenic } \\
\text { bacterium }\end{array}$ \\
\hline $\begin{array}{l}\text { D'Onofrio } \\
\text { et al. } \\
(2020)[22]\end{array}$ & $\begin{array}{l}\text { Single center } \\
\text { prospective and } \\
\text { retrospective } \\
\text { observational study } \\
\text { (Belgium) }\end{array}$ & $\begin{array}{l}\text { Both ICU } \\
\text { and non-ICU }\end{array}$ & $\begin{array}{l}110 \text { patients } \\
\text { hospitalized with } \\
\text { COVID-19 (RT-PCR), } \\
\text { Age } 73 \text { y. [60-82], } \\
\text { Male } 63 \%\end{array}$ & $\begin{array}{l}103 \text { hospitalized } \\
\text { patients with } \\
\text { influenza, } \\
\text { Age } 76 \mathrm{y} .[57-84] \text {, } \\
\text { Male } 51 \%\end{array}$ & $\begin{array}{l}\text { Blood cultures were drawn at } \\
\text { admission }(<24 \mathrm{~h})\end{array}$ \\
\hline $\begin{array}{l}\text { Engsbro et al. } \\
(2020)[27]\end{array}$ & $\begin{array}{l}\text { Single center } \\
\text { prospective } \\
\text { observational cohort } \\
\text { study (Denmark) }\end{array}$ & $\begin{array}{l}\text { Both ICU } \\
\text { and non-ICU }\end{array}$ & $\begin{array}{l}227 \text { hospitalized } \\
\text { patients with } \\
\text { COVID-19 (RT-PCR); } \\
\text { Age } 66.3 \mathrm{y} . \pm 17 \\
\text { Male } 51 \%\end{array}$ & $\begin{array}{l}2097 \text { hospitalized } \\
\text { patients }\end{array}$ & $\begin{array}{l}\text { Bloodstream infections were } \\
\text { categorized as community-acquired } \\
\text { or hospital-acquired if cultures were } \\
\text { drawn within or after } 48 \mathrm{~h} \text { of } \\
\text { admission. Clinical significance } \\
\text { assessed by microbiologist }\end{array}$ \\
\hline
\end{tabular}


Table 1. Cont.

\begin{tabular}{llllll}
\hline $\begin{array}{l}\text { Authors } \\
\text { (Year) }\end{array}$ & $\begin{array}{l}\text { Design of the Study } \\
\text { (Country) }\end{array}$ & Setting & Population & $\begin{array}{l}\text { Comparison Group } \\
\text { (non COVID-19): }\end{array}$ & Definitions \\
\hline $\begin{array}{l}\text { Fakih et al. } \\
(2021)[18]\end{array}$ & $\begin{array}{l}\text { Retrospective study } \\
\text { (USA) }\end{array}$ & $\begin{array}{l}\text { Both ICU } \\
\text { and non-ICU }\end{array}$ & $\begin{array}{l}18,048 \text { hospitalized } \\
\text { patients with } \\
\text { COVID-19 }\end{array}$ & Hospitalized patients & NA \\
\hline
\end{tabular}

Garcia-Vidal Single center

et al. observational cohort (2021) [43]
989 hospitalized

adults with

COVID-19 (RT- PCR),

Both ICU and non-ICU

tested for BSI

Age 62 y. [48-74],

Male $56 \%$
NA

Non-skin flora commensal on one or more blood culture or common skin colonizer in two or more blood cultures from different sites, plus clinical suspect.

Community-acquired diagnosis within the first $24 \mathrm{~h}$ of admission Hospital-acquired $>48 \mathrm{~h}$ after admission

\section{ICU-acquired BSI}

At least one positive blood culture for bacteria or fungi, drawn at $>48 \mathrm{~h}$ after ICU admission. For other common skin contaminants, at least two consecutive blood cultures were positive for the same pathogen. In patients with multiple blood cultures that were positive for the same organism, novel BSI events were considered as independent if occurring at least 30 days after the previous event. Polymicrobial infections were considered as separate BSI events, one for each causative organism isolated from the blood culture

CRBSI diagnosed with blood culture performed by the catheter that showed microbial growth at least $2 \mathrm{~h}$ earlier than growth detected in blood collected simultaneously from a peripheral vein

\begin{tabular}{|c|c|c|c|c|c|}
\hline $\begin{array}{l}\text { Girona- } \\
\text { Alarcon et al. } \\
\text { (2020) [26] }\end{array}$ & $\begin{array}{l}\text { Single center } \\
\text { prospective } \\
\text { observational study } \\
\text { (Spain) }\end{array}$ & ICU & $\begin{array}{l}16 \text { patients with } \\
\text { COVID-19 (PCR) } \\
\text { admitted to ICU } \\
\text { Age } 32 \text { y. [23.3-41.5] } \\
\text { Male } 56.3 \%\end{array}$ & NA & \\
\hline $\begin{array}{l}\text { Grasselli } \\
\text { et al. } \\
\text { (2021) [55] }\end{array}$ & $\begin{array}{l}\text { Multicenter } \\
\text { retrospective analysis } \\
\text { of prospectively } \\
\text { collected data } \\
\text { (Italy) }\end{array}$ & ICU & $\begin{array}{l}774 \text { patients with } \\
\text { COVID-19 admitted } \\
\text { to ICU; } \\
\text { Age } 62 \text { y. [54-68] } \\
\text { Male } 77 \%\end{array}$ & NA & $\begin{array}{l}\text { Infections were considered as ICU } \\
\text { acquired infections whether they } \\
\text { occurred } \geq 48 \mathrm{~h} \text { from ICU admission }\end{array}$ \\
\hline $\begin{array}{l}\text { Haedo et al. } \\
\text { (2020) [24] }\end{array}$ & $\begin{array}{l}\text { Single center } \\
\text { secondary analysis of } \\
\text { a prospective } \\
\text { observational study } \\
\text { (Argentina) }\end{array}$ & $\begin{array}{l}\text { Both ICU } \\
\text { and non-ICU }\end{array}$ & $\begin{array}{l}53 \text { hospitalized } \\
\text { patients with } \\
\text { COVID-19 } \\
\text { (RT-PCR) }\end{array}$ & NA & NA \\
\hline $\begin{array}{l}\text { Hughes et al. } \\
\text { (2020) [10] }\end{array}$ & $\begin{array}{l}\text { Multicenter } \\
\text { retrospective } \\
\text { observational study } \\
\text { (UK) }\end{array}$ & $\begin{array}{l}\text { Both ICU } \\
\text { and non-ICU }\end{array}$ & $\begin{array}{l}836 \text { hospitalized } \\
\text { patients with } \\
\text { confirmed } \\
\text { SARS-CoV-2 (RT- } \\
\text { PCR), } \\
\text { Age } 69.5 \text { y. [55-81], } \\
\text { Male } 62 \%\end{array}$ & $\begin{array}{l}\text { Historical cohort of } \\
216 \text { hospitalized } \\
\text { patients positive to } \\
\text { influenza A or B } \\
\text { Age } 36 \text { y. [22-65], } \\
\text { Male } 42 \%\end{array}$ & $\begin{array}{l}\text { Commensal } \\
\text { Pathogens not warranting targeted } \\
\text { therapy; } \\
\text { Community acquired infection } \\
\text { Less than } 120 \mathrm{~h} \text { from admission; } \\
\text { Hospital acquired infection } \\
\text { More than } 120 \mathrm{~h} \text { from admission }\end{array}$ \\
\hline
\end{tabular}


Table 1. Cont.

\begin{tabular}{|c|c|c|c|c|c|}
\hline $\begin{array}{l}\text { Authors } \\
\text { (Year) }\end{array}$ & $\begin{array}{l}\text { Design of the Study } \\
\text { (Country) }\end{array}$ & Setting & Population & $\begin{array}{l}\text { Comparison Group } \\
\text { (non COVID-19): }\end{array}$ & Definitions \\
\hline $\begin{array}{l}\text { Karaba et al. } \\
(2020)[13]\end{array}$ & $\begin{array}{l}\text { Multicenter } \\
\text { retrospective } \\
\text { observational study } \\
\text { (USA) }\end{array}$ & $\begin{array}{l}\text { Both ICU } \\
\text { and non-ICU }\end{array}$ & $\begin{array}{l}1016 \text { hospitalized } \\
\text { patients with } \\
\text { COVID-19 (NAAT), } \\
\text { Age } 61 \text { [48-74], Male } \\
54 \%\end{array}$ & NA & $\begin{array}{l}\text { BSI } \\
\text { Organisms recovered from blood } \\
\text { culture and deemed not to be a } \\
\text { contaminant. Co-infections were } \\
\text { considered present at the time of } \\
\text { admission (initial } 48 \mathrm{~h} \text { ) }\end{array}$ \\
\hline $\begin{array}{l}\text { Karami et al. } \\
(2021)[17]\end{array}$ & $\begin{array}{l}\text { Multicenter } \\
\text { retrospective } \\
\text { observational study } \\
\text { (The Netherlands) }\end{array}$ & $\begin{array}{l}\text { Both ICU } \\
\text { and non-ICU }\end{array}$ & $\begin{array}{l}925 \text { hospitalized } \\
\text { patients with } \\
\text { COVID-19 (PCR), } \\
\text { Age } 70 \text { y. [59-77], } \\
\text { Male } 64 \%\end{array}$ & NA & $\begin{array}{l}\text { Bacterial co-infection was defined as } \\
\text { the isolation of a bacterium from a } \\
\text { blood culture. Typical contaminants } \\
\text { were excluded. The early phase was } \\
\text { defined as the first } 7 \text { calendar days of } \\
\text { admission. }\end{array}$ \\
\hline $\begin{array}{l}\text { Karruli et al. } \\
\text { (2021) [42] }\end{array}$ & $\begin{array}{l}\text { Single center } \\
\text { retrospective } \\
\text { observational study } \\
\text { (Italy) }\end{array}$ & $\mathrm{ICU}$ & $\begin{array}{l}32 \text { patients with } \\
\text { COVID-19 admitted } \\
\text { to ICU; Age } 68 \mathrm{y} \text {. } \\
\text { [55.2-75]; } \\
\text { Male } 71.9 \%\end{array}$ & NA & $\begin{array}{l}\text { Infections were diagnosed based on } \\
\text { the current US Centers for Disease } \\
\text { Control and Prevention National } \\
\text { Health care Safety Network criteria. } \\
\text { Multidrug resistance was defined } \\
\text { according to the Magiorakos et al. } \\
\text { criteria. }\end{array}$ \\
\hline $\begin{array}{l}\text { Kokkoris } \\
\text { et al. }(2021) \\
{[15]}\end{array}$ & $\begin{array}{l}\text { Single center } \\
\text { retrospective } \\
\text { observational study } \\
\text { (Greece) }\end{array}$ & $\mathrm{ICU}$ & $\begin{array}{l}50 \text { patients with } \\
\text { COVID-19, admitted } \\
\text { to ICU } \\
\text { Age } 64 \mathrm{y} \text {. } \\
\text { Male } 76 \%\end{array}$ & NA & $\begin{array}{l}\text { ICU-acquired BSI pathogen isolation } \\
\text { from } \geq 1 \text { blood specimen obtained at } \\
\text { more than } 48 \mathrm{~h} \text { after ICU admission. } \\
\text { In patients with } \geq 2 \text { BSIs, only the first } \\
\text { BSI was included, unless the } \\
\text { subsequent episode was fungal }\end{array}$ \\
\hline $\begin{array}{l}\text { Kumar et al. } \\
(2020)[41]\end{array}$ & $\begin{array}{l}\text { Single center } \\
\text { retrospective } \\
\text { observational study } \\
\text { (USA) }\end{array}$ & $\begin{array}{l}\text { Both ICU } \\
\text { and non-ICU }\end{array}$ & $\begin{array}{l}1565 \text { hospitalized } \\
\text { patients with } \\
\text { COVID-19 }\end{array}$ & NA & $\begin{array}{l}\text { Hospital acquired BSI if cultures were } \\
\text { positive and obtained after } 3 \text { days of } \\
\text { hospital admission }\end{array}$ \\
\hline $\begin{array}{l}\text { Lardaro et al. } \\
\text { (2021) [34] }\end{array}$ & $\begin{array}{l}\text { Multicenter } \\
\text { retrospective } \\
\text { observational study } \\
\text { (USA) }\end{array}$ & $\begin{array}{l}\text { Both ICU } \\
\text { and non-ICU }\end{array}$ & $\begin{array}{l}542 \text { hospitalized } \\
\text { patients with } \\
\text { COVID-19 (RT-PCR), } \\
\text { Age } 62.8 \mathrm{y} . \pm 16.5 \\
\text { Male } 49.6 \%\end{array}$ & NA & $\begin{array}{l}\text { True positive bacteremia } \\
\text { At least two of four bottles grew } \\
\text { bacteria. The growth of bacteria } \\
\text { outside of typical skin flora was } \\
\text { generally considered true positive }\end{array}$ \\
\hline $\begin{array}{l}\text { Lendorf et al. } \\
\text { (2020) [25] }\end{array}$ & $\begin{array}{l}\text { Single center } \\
\text { retrospective } \\
\text { observational study } \\
\text { (Denmark) }\end{array}$ & $\begin{array}{l}\text { Both ICU } \\
\text { and non-ICU }\end{array}$ & $\begin{array}{l}110 \text { hospitalized } \\
\text { patients with } \\
\text { COVID-19 (RT-PCR) } \\
\text { Age } 68 \text { y. (56-78) } \\
\text { Male } 60 \%\end{array}$ & NA & $\begin{array}{l}\text { Samples were acquired within } 3 \text { days } \\
\text { of hospitalization. Clinically relevant } \\
\text { if likely to contribute to } \\
\text { symptomatology and guided } \\
\text { treatment }\end{array}$ \\
\hline $\begin{array}{l}\text { Marcus et al. } \\
(2021)[44]\end{array}$ & $\begin{array}{l}\text { Single center } \\
\text { retrospective } \\
\text { observational study } \\
\text { (USA) }\end{array}$ & ICU & $\begin{array}{l}17 \text { patients with } \\
\text { COVID-19 admitted } \\
\text { to ICU and treated } \\
\text { with ECMO; } \\
\text { Age } 42 \text { y. [35-49], } \\
\text { Male } 76 \%\end{array}$ & $\begin{array}{l}22 \text { patients with } \\
\text { influenza admitted to } \\
\text { ICU and treated with } \\
\text { ECMO; } \\
\text { Age } 45 \text { y. [35-55], } \\
\text { Male } 68 \%\end{array}$ & $\begin{array}{l}\text { BSI } \\
\text { Positive cultures during ECMO course } \\
\text { or within } 48 \mathrm{~h} \text { of decannulation that } \\
\text { were determined to be pathogenic by } \\
\text { the patient's treatment team }\end{array}$ \\
\hline $\begin{array}{l}\text { Martinez- } \\
\text { Guerra et al. } \\
(2021) \text { [48] }\end{array}$ & $\begin{array}{l}\text { Single center } \\
\text { prospective cohort } \\
\text { study } \\
\text { (Mexico) }\end{array}$ & $\begin{array}{l}\text { Both ICU } \\
\text { and non-ICU }\end{array}$ & $\begin{array}{l}794 \text { hospitalized } \\
\text { patients with } \\
\text { COVID-19 (RT-PCR) } \\
\text { (data presented on } \\
656 \text { patients with } \\
\text { complete follow-up) } \\
\text { Age } 52 \text { y. [43-62] } \\
\text { Male } 61.6 \%\end{array}$ & NA & NA \\
\hline $\begin{array}{l}\text { Nori et al. } \\
(2021) \text { [54] }\end{array}$ & $\begin{array}{l}\text { Multicenter } \\
\text { retrospective } \\
\text { observational study } \\
\text { (USA) }\end{array}$ & $\begin{array}{l}\text { Both ICU } \\
\text { and non-ICU }\end{array}$ & $\begin{array}{l}152 \text { hospitalized } \\
\text { patients with } \\
\text { COVID-19 (PCR) } \\
\text { Age } 62 \text { y. [52.5-72] } \\
\text { Male } 59 \%\end{array}$ & NA & $\begin{array}{l}\text { All cases were reviewed by an } \\
\text { infectious diseases specialist to } \\
\text { determine the presence of true clinical } \\
\text { coinfection and the source. National } \\
\text { Healthcare Safety Network criteria } \\
\text { were used for central-line-associated } \\
\text { bloodstream infections }\end{array}$ \\
\hline
\end{tabular}


Table 1. Cont.

\begin{tabular}{|c|c|c|c|c|}
\hline $\begin{array}{l}\text { Authors } \\
\text { (Year) }\end{array}$ & $\begin{array}{l}\text { Design of the Study } \\
\text { (Country) }\end{array}$ & Setting & Population & $\begin{array}{l}\text { Comp } \\
\text { (non }\end{array}$ \\
\hline $\begin{array}{l}\text { Ripa et al. } \\
(2021) \text { [52] }\end{array}$ & $\begin{array}{l}\text { Single center } \\
\text { prospective } \\
\text { observational study } \\
\text { (Italy) }\end{array}$ & $\begin{array}{l}\text { Both ICU } \\
\text { and non-ICU }\end{array}$ & $\begin{array}{l}731 \text { hospitalized } \\
\text { patients with } \\
\text { COVID-19 (RT-PCR), } \\
\text { Age } 64 \text { [55-76], Male } \\
67.9 \%\end{array}$ & NA \\
\hline
\end{tabular}

Comparison Group $\quad$ Definitions
(non COVID-19):

\section{BSI}

Single positive blood culture for a likely pathogen or two or more positive blood cultures for common skin colonizers without a concomitant microbiologically documented lower respiratory tract infection due to the same pathogen.

Patients with more than one positive blood culture within 7 days from the first positive blood culture were considered to have a single episode of BSI with multiple isolates

\begin{tabular}{|c|c|c|c|c|c|}
\hline $\begin{array}{l}\text { Rothe et al. } \\
\text { (2021) [40] }\end{array}$ & $\begin{array}{l}\text { Single center } \\
\text { retrospective } \\
\text { observational study } \\
\text { (Germany) }\end{array}$ & $\begin{array}{l}\text { Both ICU } \\
\text { and non-ICU }\end{array}$ & $\begin{array}{l}140 \text { hospitalized } \\
\text { patients with } \\
\text { COVID-19 (RT-PCR } \\
\text { or serological); } \\
\text { Age } 63.5 \text { y. (range } \\
\text { 17-99); } \\
\text { Male } 64 \%\end{array}$ & NA & $\begin{array}{l}\text { In case of coagulase-negative } \\
\text { staphylococci, the isolates were } \\
\text { considered clinically significant (true } \\
\text { bacteraemia) if two or more bottles } \\
\text { yielded the same microorganism. }\end{array}$ \\
\hline $\begin{array}{l}\text { Søgaard et al. } \\
(2021) \text { [29] }\end{array}$ & $\begin{array}{l}\text { Single center } \\
\text { retrospective } \\
\text { observational study } \\
\text { (Switzerland) }\end{array}$ & $\begin{array}{l}\text { Both ICU } \\
\text { and non-ICU }\end{array}$ & $\begin{array}{l}162 \text { hospitalized } \\
\text { patients with } \\
\text { COVID-19 (RT-PCR), } \\
\text { Age } 64.4 \mathrm{y} \text {. } \\
\text { [50.4-74.2] } \\
\text { Male } 61.1 \%\end{array}$ & NA & $\begin{array}{l}\text { Community-acquired bloodstream } \\
\text { infection } \\
\text { pathogen from a blood culture } \\
\text { taken within } 48 \text { h of hospitalization. } \\
\text { Hospital-acquired bloodstream } \\
\text { infection } \\
\text { pathogen from a blood culture taken } \\
48 \text { h or more after hospitalization. }\end{array}$ \\
\hline $\begin{array}{l}\text { Soriano et al. } \\
(2021) \text { [31] }\end{array}$ & $\begin{array}{l}\text { Single center } \\
\text { restrospective } \\
\text { observational study } \\
\text { (Spain) }\end{array}$ & ICU & $\begin{array}{l}83 \text { patients with } \\
\text { COVID-19 (RT-PCR) } \\
\text { admitted to ICU, } \\
\text { Age } 61.2 \mathrm{y} . \pm 10.4 \\
\text { Male } 79.5 \%\end{array}$ & NA & NA \\
\hline $\begin{array}{l}\text { Suarez de la } \\
\text { Rica } \\
\text { et al.(2021) } \\
\text { [32] }\end{array}$ & $\begin{array}{l}\text { Single center } \\
\text { retrospective study } \\
\text { (Spain) }\end{array}$ & ICU & $\begin{array}{l}107 \text { patients with } \\
\text { COVID-19 (RT-PCR), } \\
\text { admitted to ICU, } \\
\text { Age } 62.2 \mathrm{y} . \pm 10.6, \\
\text { Male } 71 \%\end{array}$ & NA & $\begin{array}{l}\text { Nosocomial bacteremia } \\
\text { positive blood cultures recovered at } \\
\text { least } 48 \mathrm{~h} \text { after the hospital admission. } \\
\text { Coagulase-negative staphylococci } \\
\text { considered as contaminants (only one } \\
\text { positive blood culture) were excluded }\end{array}$ \\
\hline $\begin{array}{l}\text { Thelen et al. } \\
\text { (2021) [20] }\end{array}$ & $\begin{array}{l}\text { Multicenter } \\
\text { retrospective cohort } \\
\text { study } \\
\text { (The Netherlands) }\end{array}$ & $\begin{array}{l}\text { Both ICU } \\
\text { and non-ICU }\end{array}$ & $\begin{array}{l}678 \text { hospitalized } \\
\text { patients with } \\
\text { COVID-19 (RT-PCR), } \\
\text { Age } 70 \text { y. [58-78], } \\
\text { Male } 65 \%\end{array}$ & $\begin{array}{l}653 \text { patients with } \\
\text { influenza A or B } \\
\text { (RT-PCR) }\end{array}$ & $\begin{array}{l}\text { Bacteria were categorized as likely } \\
\text { contaminants if they were affiliated to } \\
\text { groups that represent commensal skin } \\
\text { microbiota and were defined in the } \\
\text { patient's medical record as a } \\
\text { contaminant by the Department of } \\
\text { Medical Microbiology. Blood cultures } \\
\text { were collected within a time interval } \\
\text { of } 48 \text { h before and after the RT-PCR } \\
\text { test }\end{array}$ \\
\hline $\begin{array}{l}\text { Vaughn et al. } \\
(2020) \text { [11] }\end{array}$ & $\begin{array}{l}\text { Multicenter } \\
\text { retrospective } \\
\text { observational study } \\
\text { (USA) }\end{array}$ & $\begin{array}{l}\text { Both ICU } \\
\text { and non-ICU }\end{array}$ & $\begin{array}{l}1705 \text { hospitalized } \\
\text { patients with } \\
\text { COVID-19, } \\
\text { Age y. } 64.7 \text { [53-76.7], } \\
\text { Male } 52 \%\end{array}$ & NA & $\begin{array}{l}\text { Community onset bacterial } \\
\text { coinfections were identified by blood } \\
\text { culture positive for a typically } \\
\text { pathogenic bacterium }\end{array}$ \\
\hline $\begin{array}{l}\text { Wang et al. } \\
\text { (2021) [19] }\end{array}$ & $\begin{array}{l}\text { Multicenter } \\
\text { retrospective } \\
\text { observational cohort } \\
\text { study } \\
\text { (UK) }\end{array}$ & $\begin{array}{l}\text { Both ICU } \\
\text { and non-ICU }\end{array}$ & $\begin{array}{l}1396 \text { hospitalized } \\
\text { patients with } \\
\text { COVID-19 (RT-PCR), } \\
\text { Age } 67.4 \mathrm{y} . \pm 16.2, \\
\text { Male } 64.7 \%\end{array}$ & NA & $\begin{array}{l}\text { Microbiological specimens taken } \\
\text { within } 48 \mathrm{~h} \text { of admission. } \\
\text { Two senior consultant microbiologists } \\
\text { reviewed the clinical significance of } \\
\text { the test results and the likelihood of } \\
\text { contamination or colonization based } \\
\text { on the nature of the isolated } \\
\text { organisms }\end{array}$ \\
\hline
\end{tabular}


Table 1. Cont.

\begin{tabular}{|c|c|c|c|c|c|}
\hline $\begin{array}{l}\text { Authors } \\
\text { (Year) }\end{array}$ & $\begin{array}{l}\text { Design of the Study } \\
\text { (Country) }\end{array}$ & Setting & Population & $\begin{array}{l}\text { Comparison Group } \\
\text { (non COVID-19): }\end{array}$ & Definitions \\
\hline $\begin{array}{l}\text { Wendel } \\
\text { Garcia et al. } \\
(2020)[46]\end{array}$ & $\begin{array}{l}\text { Multicenter } \\
\text { prospective } \\
\text { observational cohort } \\
\text { study } \\
\text { (EU) }\end{array}$ & ICU & $\begin{array}{l}639 \text { patients with } \\
\text { COVID-19 admitted } \\
\text { to ICU (data } \\
\text { presented on } 398 \\
\text { patients who reached } \\
\text { the outcome of } \\
\text { discharged/dead) } \\
\text { Age } 63 \text { [53-71]; Male } \\
75 \%\end{array}$ & NA & $\begin{array}{l}\text { Bacteraemia and fungaemia were } \\
\text { defined as positive blood cultures for } \\
\text { a bacterial or fungal pathogen }\end{array}$ \\
\hline $\begin{array}{l}\text { Zhang et al. } \\
\text { (2020) [51] }\end{array}$ & $\begin{array}{l}\text { Multicenter } \\
\text { retrospective cohort } \\
\text { study } \\
\text { (China) }\end{array}$ & $\begin{array}{l}\text { Both ICU } \\
\text { and non-ICU }\end{array}$ & $\begin{array}{l}38 \text { patients with } \\
\text { severe or critical } \\
\text { COVID-19, } \\
\text { Age } 64.76 \text { y. } \pm 13.76 \text {, } \\
\text { Male } 84 \%\end{array}$ & NA & $\begin{array}{l}\text { Secondary infection clinical } \\
\text { symptoms or positive radiologic } \\
\text { evidence and a positive } \\
\text { laboratory-confirmed aetiologic result } \\
\text { (culture positive or mNGS positive } \\
\text { confirming by RT-PCR) after } 48 \text { h of } \\
\text { admission. The final diagnosis of } \\
\text { causative agents was made according } \\
\text { to the clinical physician expert groups' } \\
\text { discussion results }\end{array}$ \\
\hline $\begin{array}{l}\text { Zhou et al. } \\
(2020) \text { [23] }\end{array}$ & $\begin{array}{l}\text { Multicenter } \\
\text { retrospective } \\
\text { observational study } \\
\text { (China) }\end{array}$ & $\begin{array}{l}\text { Both ICU } \\
\text { and non-ICU }\end{array}$ & $\begin{array}{l}195 \text { patients with } \\
\text { COVID-19 (RT-PCR), } \\
\text { admitted to ICU, } \\
\text { Age } 66 \text { y. [56-76], } \\
\text { Male } 66.7 \%\end{array}$ & NA & NA \\
\hline
\end{tabular}

\subsection{Outcomes}

All the included studies reported the occurrence of BSI in cohorts of hospitalized patients with COVID-19. The pooled estimated occurrence of BSI was $7.3 \%$ (95\% CI $4.7-1.1 \% ; 1324 / 42,694$ patients; $\mathrm{I}^{2}=98 \%$; Figure $2 \mathrm{a}$ ).

Fourteen studies $[6,10,18,20,27,28,32,34,35,38,42,46,50,55]$ reported data on mortality in patients with COVID-19 and BSI. The pooled estimated occurrence of mortality (at the longest available follow-up) was $41 \%$ ( $95 \%$ CI $30 \%-52.8 \%$; $189 / 482$ patients; $\mathrm{I}^{2}=78 \%$; Figure 3).

\subsection{Sensitivity and Subgroup Analyses}

The pooled estimate of the occurrence of BSI in patients admitted to ICUs was $29.6 \%$ (95\% CI 21.7\%-38.8\%; 558/2487 patients; $\mathrm{I}^{2}=93 \%$; Figure $2 b$ ).

Concerning the occurrence of BSI based on the number of centers, the pooled estimate was $4.7 \%$ (95\% CI 2.5-8.7\%; 670/14,169 patients; $I^{2}=98 \%$; Figure S1, Supplementary Material) when considering only multicenter studies and 9.1\% (95\% CI 4.9-16.5\%; 654/28,525 patients; $\mathrm{I}^{2}=98 \%$; Figure S2, Supplementary Material) when considering only single center studies.

In the post-hoc subgroup analysis, considering only data from studies specifically addressing hospital-acquired BSI, the pooled estimate of the occurrence of BSI was $12.2 \%$ (95\% CI 6.6\%-21.3\%; 606/9839 patients; I $\mathrm{I}^{2}=98 \%$; Figure S3, Supplementary Material).

We also conducted a sensitivity analysis considering the occurrence of BSI patients without COVID-19, in comparison with those with COVID-19. Eleven studies provided data on a comparison group, but one study [18] did not provide the denominator to calculate the occurrence. Thus, in this analysis, 10 studies $[6,10,12,16,20,22,27,28,35,44]$ providing unadjusted data on occurrence of BSI in the comparison group were included. There was found a significantly higher risk of BSI in patients with COVID-19 compared to patients without COVID-19 (OR 2.18; 95\% CI 1.35-3.51; $p<0.001 ; \mathrm{I}^{2}=79 \%$; Figure 4). 
a.

\section{Studies}

Adler et al. 2020

Akagi et al. 2020

Bardi et al. 2021

Barry et al. 2021

Baskaran et al. 2021

Bayo et al. 2020

Blazoski et al. 2021

Bonazzetti et al. 2020

Buehler et al. 2021

Buetti et al. 2021

Cataldo et al. 2020

Cates et al. 2020

Chen et al. 2020

Cheng et al. 2020

Contou et al. 2020

D'Onofrio et al. 2020

Engsbro et al. 2020

Fakih et al. 2021

Garcia-Vidal et al. 2021

Giacobbe et al. 2020

Gidaro et al. 2020

Girona-Alarcon et al. 2020

Grasselli et al. 2021

Haedo et al. 2020

Hughes et al. 2020

Karaba et al. 2020

Karami et al. 2021

Karruli et al. 2021

Kokkoris et al. 202

Kumar et al. 2020

Lardaro et al. 202

Lendorf tot al. 2020

Marcus et al. 2021

Martinez-Guerra et al. 202

Nori et al. 2021

Ripa et al. 2021

Rothe et al. 2021

Soegaard et al. 2021

Soriano et al. 2021

Suarez de la Rica et al. 2021

Thelen et al. 2021

Vaughn et al. 2020

Wang et al. 2021

Wendel Garcia et al. 2020

Zhang et al. 2020

Zhou et al. 2020

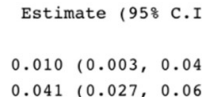

$0.041(0.027,0.061)$

$0.250(0.185,0.328)$

$0.033(0.021,0.051)$

$0.079(0.051,0.119)$

$0.015(0.011,0.020)$

$0.250(0.108,0.478)$

$0.674(0.570,0.763)$

$0.244(0.141,0.390)$

$0.149(0.109,0.200)$

$0.491(0.365,0.619)$

$0.047(0.041,0.054)$

$0.020(0.010,0.039)$

$0.033(0.016,0.068)$

$0.011(0.002,0.073)$

$0.027(0.009,0.081)$

$0.053(0.030,0.091)$

$0.003(0.002,0.004)$

$0.018(0.011,0.029)$

$0.397(0.295,0.509)$

$0.014(0.008,0.023)$

$0.437(0.225,0.676)$

$0.172(0.147,0.200)$

$0.038(0.009,0.139)$

$0.026(0.017,0.040)$

$0.020(0.013,0.030)$

$0.004(0.002,0.011)$

$0.469(0.306,0.639)$

$0.540(0.402,0.672)$

$0.034(0.026,0.044)$

$0.011(0.005,0.024)$

$0.009(0.001,0.062)$

$0.412(0.210,0.648)$

$0.050(0.036,0.070)$

$0.539(0.460,0.617)$

$0.079(0.062,0.101)$

$0.114(0.071,0.178)$

$0.037(0.017,0.080)$

$0.422(0.320,0.530)$

$0.318(0.237,0.412)$

$0.010(0.005,0.021)$

$0.018(0.013,0.026)$

$0.009(0.005,0.015)$

$0.186(0.151,0.227)$

$0.342(0.210,0.504)$

$0.051(0.028,0.093)$

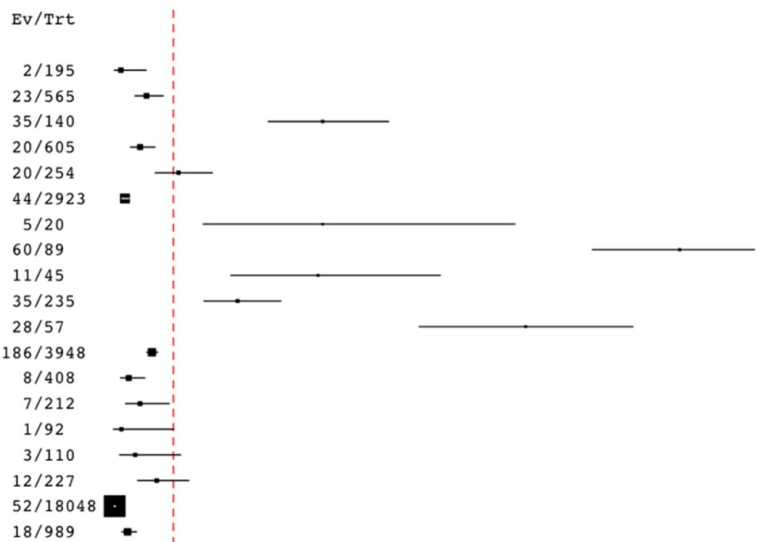

$18 / 989$

$15 / 1077$.

$7 / 16$

$133 / 774$

$2 / 53$

$22 / 836=$

$20 / 1016$ -

$4 / 925$

$15 / 32$

$27 / 50$

$6 / 542$

$1 / 110$

$33 / 656$

$82 / 152$

$58 / 73$

$16 / 140$

35/83

$35 / 83$
$34 / 107$

$34 / 107$
$7 / 678$

$31 / 1705$

$12 / 1396$

$74 / 398$

$13 / 38$

$10 / 195$

Overall $\left(I^{\wedge} 2=9819 \%, P<0.001\right) \quad 0.073(0.047,0.110) \quad 1324 / 42694$

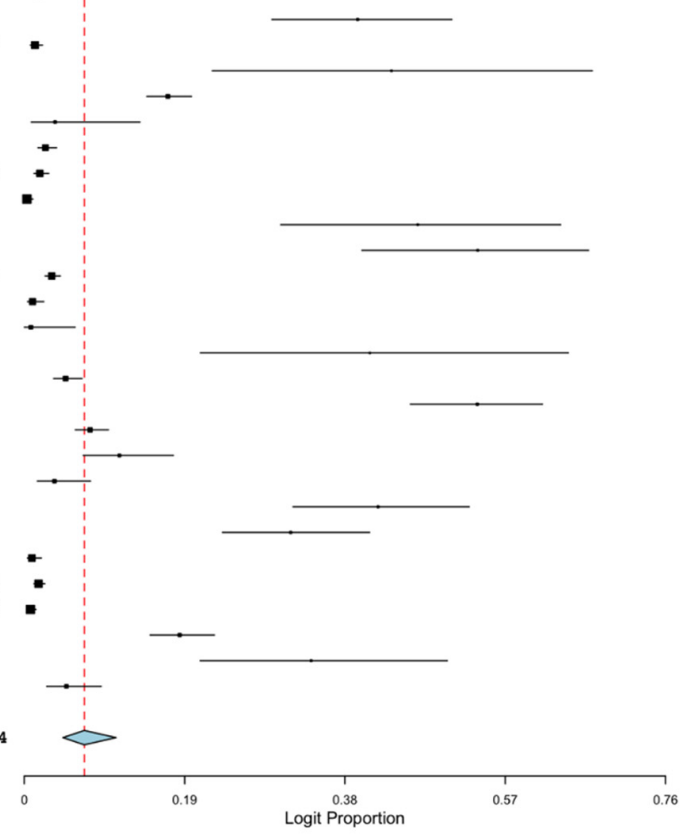

Studies

b.

Bardi et al. 202

Baskaran et al. 2021

Blazoski et al. 2021

Bonazzetti et al. 2020

Buehler et al. 202

Buetti et al. 2021

Cataldo et al. 2020

Contou et al. 2020

Giacobbe et al. 2020

Girona-Alarcon et al. 2020

Grasselli et al. 2021

Karruli et al. 2021

Kokkoris et al. 202

Kokkoris et al. 2021

Soriano et al. 2021

Suarez de la Rica et al. 2021

Wendel Garcia et al. 2020

Overall $\left(\left.\right|^{\wedge} 2=9300 \%, P<0.001\right) \quad 0.296(0.217,0.388) \quad 558 / 2487$

Estimate (958 C.I.) Ev/Trt

$0.250(0.185,0.328) \quad 35 / 140$

$0.079(0.051,0.119) \quad 20 / 254$

$0.250(0.108,0.478) \quad 5 / 20$

$0.674(0.570,0.763) \quad 60 / 89$

$0.244(0.141,0.390) \quad 11 / 45$

$0.149(0.109,0.200) \quad 35 / 235$

$0.491(0.365,0.619) \quad 28 / 57$

$0.011(0.002,0.073) \quad 1 / 92$

$0.397(0.295,0.509) \quad 31 / 78$

$0.437(0.225,0.676) \quad 7 / 16$

$0.172(0.147,0.200) 133 / 774$

$0.469(0.306,0.639) \quad 15 / 32$

$0.540(0.402,0.672) \quad 27 / 50$

$0.412(0.210,0.648) \quad 7 / 17$

$0.422(0.320,0.530) \quad 35 / 83$

$0.318(0.237,0.412) \quad 34 / 107$

$0.186(0.151,0.227) \quad 74 / 398$$$
\begin{aligned}
& \\
& 0
\end{aligned}
$$

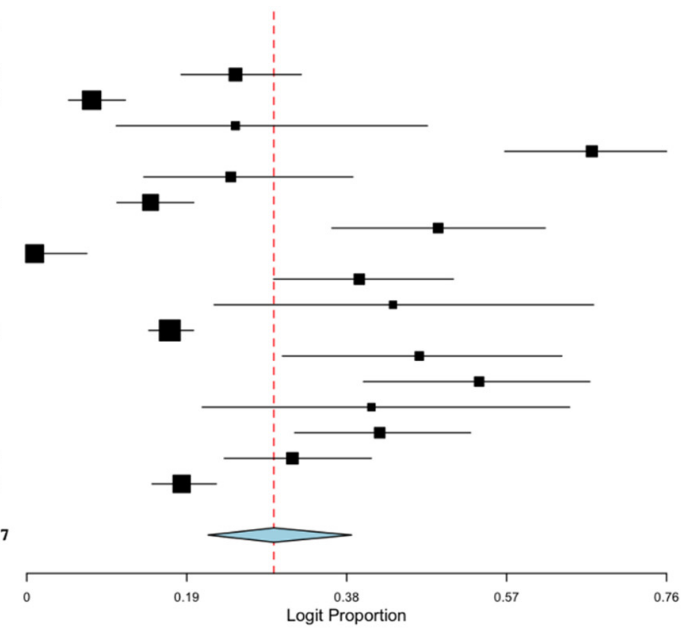

Figure 2. Occurrence of bloodstream infection. Forest plot with the result of single-arm meta-analysis for the occurrence of BSI in patients with COVID-19. BSI, bloodstream infection; CI, confidence interval; Ev, events; Trt, total. (a) Pooled estimated occurrence of bloodstream infection among hospitalized patients with COVID-19. (b) Pooled estimated occurrence of bloodstream infection among patients with COVID-19 admitted to ICU. 

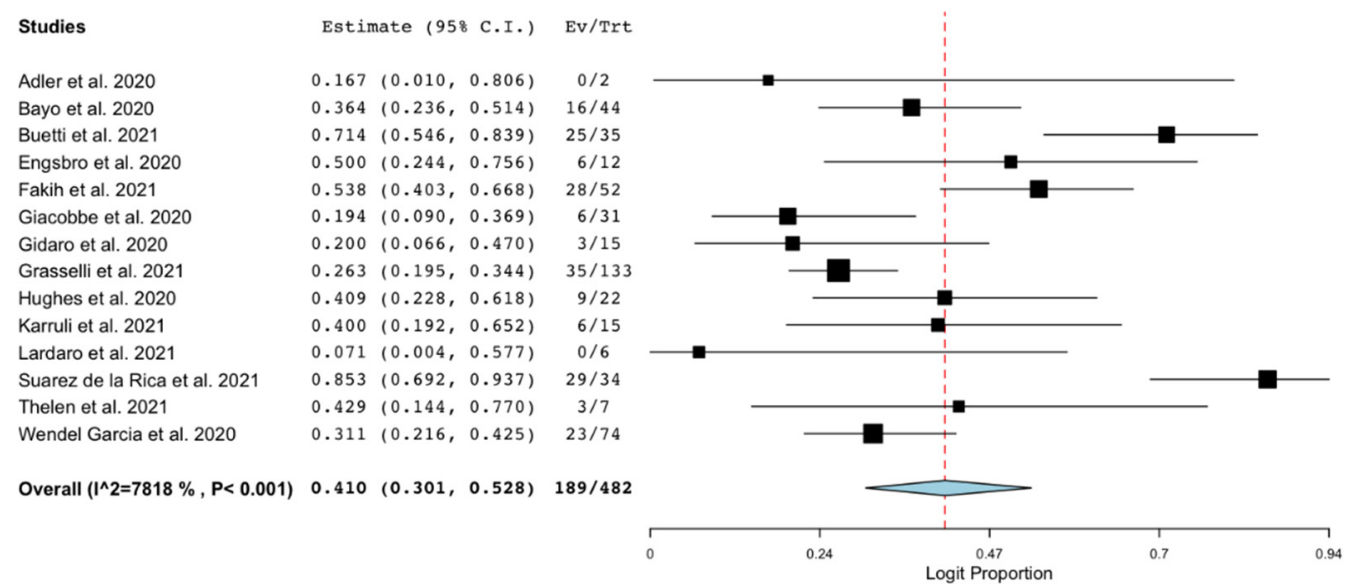

Figure 3. Mortality of patients with COVID-19 and bloodstream infection. Forest plot with the result of single-arm meta-analysis for mortality of patients with COVID-19 and BSI. BSI, bloodstream infection; CI, confidence interval; Ev, events; Trt, total.

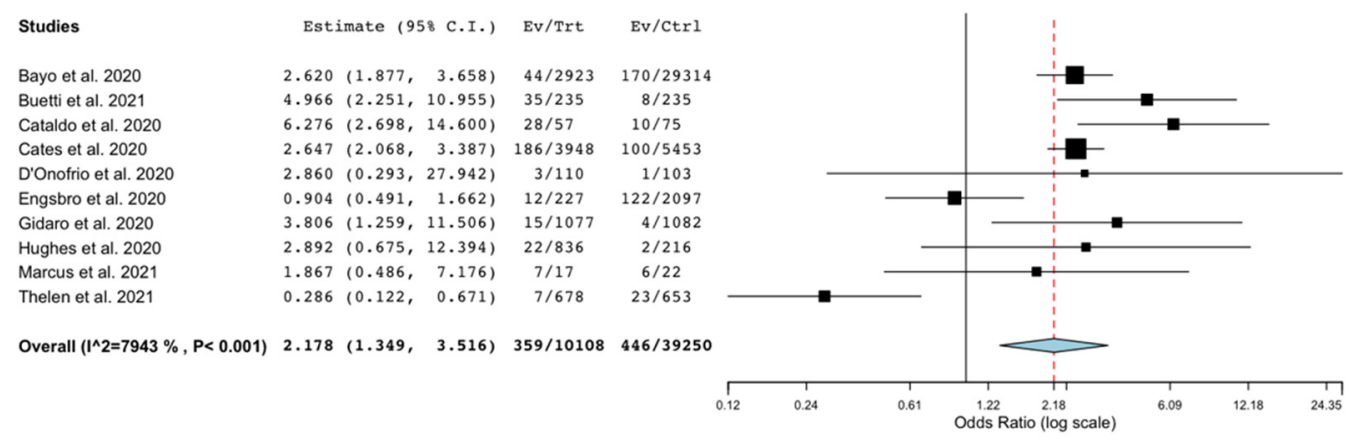

Figure 4. Occurrence of bloodstream infection in patients with COVID-19 compared with patients without COVID-19. Forest plot with the results of the sensitivity analysis on the occurrence of BSI in patients with COVID-19 compared to patients without COVID-19. BSI, bloodstream infection; CI, confidence interval; Ctrl, controls; Ev, events; Trt, total.

\section{Discussion}

To the best of our knowledge, this is the most updated systematic review and metaanalysis estimating the occurrence of BSIs among hospitalized patients with COVID19. Our main finding was that around $7 \%$ of hospitalized patients with COVID-19 may experience a BSI. This data was comparable with that measured among hospitalized patients prior to the pandemic [56]. Interestingly, around one out of three patients with COVID-19, once admitted to ICU, may have a clinical course complicated by a BSI. This finding is also in line with the previously estimated prevalence of BSIs in adult patients with sepsis or septic shock [1,57] and almost double than the prevalence of BSIs in cohorts of adult patients admitted to ICU [58].

A higher occurrence of BSI in patients with COVID-19 was also observed, in comparison with patients without COVID-19 (OR 2.77; 95\% CI 1.53-5.02; $p<0.001$ ). Although caution is needed considering this result, coming from an unadjusted analysis, the development of a BSI in patients with COVID-19 may share some risk factors with other superinfections, frequently observed in patients with COVID-19 [5,59]. Hospital and ICU overcrowding, a difficult application of infection prevention strategies while using PPE in such settings, patients' immunological impairment, and the frequent need for central lines can be counted as risk factors specifically belonging to patients with COVID-19.

During the early phases of the pandemic, many centers supported the protocolized administration of antibiotic therapy at the time of diagnosis or hospital admission due to COVID-19. Considering our data, in addition to what was already issued on the topic [60], 
that approach may not be probably justified by the real occurrence of superinfections, and a tailored approach is needed. A clinical suspect should still probably remain the condictio sine qua non to consider the beginning of an antibiotic therapy in patients with COVID-19, taking into account that those admitted to ICU may deserve specific attention.

Our study has strengths, such as the comprehensive search, the methodology, and the reporting according to PRISMA 2020 [7], the large number of studies and patients evaluated, and the geographical variety of the settings. Moreover, incompletely reported data were retrieved from the corresponding authors when feasible. Our analysis also has limitations. The nature of this study was descriptive, and no analysis was performed to look for associations with potential risk factors. Our analysis also had a high statistical heterogeneity. The high statistical heterogeneity across the studies may be attributed to the different criteria used to include patients, based on the origin of the infection (i.e., community-acquired, hospital-acquired, ICU-acquired), the variable sampling rate, or the different settings (i.e., ICU or non-ICU wards). Other factors, such as patients' characteristics or clinical severity may also explain heterogeneity. However, we tried to reduce the impact of heterogeneity with several pre-planned sensitivity and subgroup analyses. Data on causative microorganisms were also heterogeneously reported across the studies; thus, we decided to report them as per the authors' descriptions, and we did not perform any quantitative analysis on causative microorganisms.

\section{Conclusions}

A total of $7 \%$ of hospitalized patients with COVID-19 may experience BSI with a mortality rate of around $40 \%$. Almost $30 \%$ of patients admitted to the ICU may develop BSI during their ICU stay. Hospitalized patients with COVID-19 may have three-times higher odds of developing BSI than patients without COVID-19.

Supplementary Materials: The following are available online at https:/ / www.mdpi.com/article/10 .3390/microorganisms9102016/s1, PDF S1: Search strategy; PDF S2: Figure S1: Forest plot with the results of the subgroup analysis conducted on the occurrence of bloodstream infections in patients with COVID-19 in multicenter studies; Figure S2: Forest plot with the results of the subgroup analysis conducted on the occurrence of bloodstream infections in patients with COVID-19 in single center studies; Figure S3: Forest plot with the result of the post-hoc subgroup analysis, considering only data from studies specifically addressing hospital-acquired bloodstream infections; Table S1: PRISMA Main Checklist and PRISMA Abstract Checklist; Table S2: Characteristics of bloodstream infections and isolates, Table S3: Quality assessment of studies according to MINORS score for non-comparative studies; Table S4: Quality assessment of studies according to MINORS additional score for comparative studies; Excel S1: Full search output.

Author Contributions: A.C. and M.I. conceived and designed the work. M.I., B.S., C.F., F.R.C., G.C., C.M., and A.C. collected the data. M.I. and A.C. performed the analysis. G.M. and A.G. gave substantial contributions to data acquisition and interpretation for the work; M.I. and A.C. drafted the work. B.S., C.F., F.R.C., G.C., C.M., G.M., and A.G. revised the work critically for important intellectual content. All the authors gave the final approval of the version to be published and agreed to be accountable for all aspects of the work in ensuring that questions related to the accuracy or integrity of any part of the work are appropriately investigated and resolved. All authors have read and agreed to the published version of the manuscript.

Funding: This research received no external funding.

Institutional Review Board Statement: Not applicable.

Informed Consent Statement: Not applicable.

Data Availability Statement: The data presented in this study are available in Supplementary Materials. The unpublished data retrieved by private correspondence with the authors and used in this study analysis are available on request from the corresponding author.

Conflicts of Interest: The authors declare no conflict of interest. 


\section{References}

1. Timsit, J.F.; Ruppé, E.; Barbier, F.; Tabah, A.; Bassetti, M. Bloodstream infections in critically ill patients: An expert statement. Intensive Care Med. 2020, 46, 266-284. [CrossRef]

2. Russotto, V.; Cortegiani, A.; Graziano, G.; Saporito, L.; Raineri, S.M.; Mammina, C.; Giarratano, A. Bloodstream infections in intensive care unit patients: Distribution and antibiotic resistance of bacteria. Infect. Drug Resist. 2015, 8, 287-296. [CrossRef] [PubMed]

3. Blyth, C.C.; Webb, S.A.R.; Kok, J.; Dwyer, D.E.; van Hal, S.J.; Foo, H.; Ginn, A.N.; Kesson, A.M.; Seppelt, I.; Iredell, J.R.; et al. The impact of bacterial and viral co-infection in severe influenza. Influenza Other Respir. Viruses 2013, 7, 168-176. [CrossRef] [PubMed]

4. Martín-Loeches, I.; Sanchez-Corral, A.; Diaz, E.; Granada, R.M.; Zaragoza, R.; Villavicencio, C.; Albaya, A.; Cerdá, E.; Catalán, R.M.; Luque, P.; et al. Community-acquired respiratory coinfection in critically III patients with pandemic 2009 influenza A(H1N1) virus. Chest 2011, 139, 555-562. [CrossRef]

5. Ippolito, M.; Misseri, G.; Catalisano, G.; Marino, C.; Ingoglia, G.; Alessi, M.; Consiglio, E.; Gregoretti, C.; Giarratano, A.; Cortegiani, A. Ventilator-associated pneumonia in patients with covid-19: A systematic review and meta-analysis. Antibiotics 2021, 10, 545. [CrossRef] [PubMed]

6. Buetti, N.; Ruckly, S.; de Montmollin, E.; Reignier, J.; Terzi, N.; Cohen, Y.; Shiami, S.; Dupuis, C.; Timsit, J.F. COVID-19 increased the risk of ICU-acquired bloodstream infections: A case-cohort study from the multicentric OUTCOMEREA network. Intensive Care Med. 2021, 47, 180-187. [CrossRef] [PubMed]

7. Page, M.; McKenzie, J.; Bossuyt, P.; Boutron, I.; Hoffmann, T.; Mulrow, C.; Shamseer, L.; Tetzlaff, J.M.; Akl, E.A.; Brennan, S.E.; et al. The PRISMA 2020 statement: An updated guideline for reporting systematic reviews. BMJ 2021, 372, n71. [CrossRef]

8. Slim, K.; Nini, E.; Forestier, D.; Kwiatkowski, F.; Panis, Y.; Chipponi, J. Methodological index for non-randomized studies (Minors): Development and validation of a new instrument. ANZ J. Surg. 2003, 73, 712-716. [CrossRef]

9. Wallace, B.C.; Dahabreh, I.J.; Trikalinos, T.A.; Lau, J.; Trow, P.; Schmid, C.H. Open Meta Analyst; Closing the gap between methodologists and end-users: R as a computational back-end. Stat. Softw. 2012, 49, 1-15.

10. Hughes, S.; Troise, O.; Donaldson, H.; Mughal, N.; Moore, L.S.P. Bacterial and fungal coinfection among hospitalized patients with COVID-19: A retrospective cohort study in a UK secondary-care setting. Clin. Microbiol. Infect. 2020, 26, 1395-1399. [CrossRef]

11. Vaughn, V.M.; Gandhi, T.N.; Petty, L.A.; Patel, P.K.; Prescott, H.C.; Malani, A.N.; Ratz, D.; McLaughlin, E.; Chopra, V.; Flanders, S.A. Empiric Antibacterial Therapy and Community-onset Bacterial Coinfection in Patients Hospitalized With Coronavirus Disease 2019 (COVID-19): A Multi-hospital Cohort Study. Clin. Infect. Dis. 2021, 72, e533-e541. [CrossRef]

12. Cataldo, M.A.; Tetaj, N.; Selleri, M.; Marchioni, L.; Capone, A.; Caraffa, E.; Di Caro, A.; Petrosillo, N. Incidence of bacterial and fungal bloodstream infections in COVID-19 patients in intensive care: An alarming "collateral effect". J. Glob. Antimicrob. Resist. 2020, 23, 290-291. [CrossRef]

13. Karaba, S.M.; Jones, G.; Helsel, T.; Smith, L.L.; Avery, R.; Dzintars, K.; Salinas, A.B.; Keller, S.C.; Townsend, J.L.; Klein, E.; et al. Prevalence of co-infection at the time of hospital admission in COVID-19 Patients, A multicenter study. Open Forum Infect. Dis. 2021, 8. [CrossRef] [PubMed]

14. Bardi, T.; Pintado, V.; Gomez-Rojo, M.; Escudero-Sanchez, R.; Azzam Lopez, A.; Diez-Remesal, Y.; Martinez Castro, N.; RuizGarbajosa, P.; Pestaña, D. Nosocomial infections associated to COVID-19 in the intensive care unit: Clinical characteristics and outcome. Eur. J. Clin. Microbiol. Infect. Dis. 2021, 40, 495-502. [CrossRef] [PubMed]

15. Kokkoris, S.; Papachatzakis, I.; Gavrielatou, E.; Ntaidou, T.; Ischaki, E.; Malachias, S.; Vrettou, C.; Nichlos, C.; Kanavou, A.; Zervakis, D.; et al. ICU-acquired bloodstream infections in critically ill patients with COVID-19. J. Hosp. Infect. 2021, 107, 95-97. [CrossRef] [PubMed]

16. Cates, J.; Lucero-Obusan, C.; Dahl, R.M.; Schirmer, P.; Garg, S.; Oda, G.; Hall, A.J.; Langley, G.; Havers, F.P.; Holodniy, M.; et al. Risk for In-Hospital Complications Associated with COVID-19 and Influenza-Veterans Health Administration, United States, October 1, 2018-May 31, 2020. MMWR Morb. Mortal. Wkly. Rep. 2020, 69, 1528-1534. [CrossRef]

17. Karami, Z.; Knoop, B.T.; Dofferhoff, A.S.M.; Blaauw, M.J.T.; Janssen, N.A.; van Apeldoorn, M.; Kerckhoffs, A.P.M.; van de Maat, J.S.; Hoogerwerf, J.J.; ten Oever, J. Few bacterial co-infections but frequent empiric antibiotic use in the early phase of hospitalized patients with COVID-19: Results from a multicentre retrospective cohort study in The Netherlands. Infect. Dis. (Auckl.) 2021, 53, 102-110. [CrossRef]

18. Fakih, M.G.; Bufalino, A.; Sturm, L.; Huang, R.H.; Ottenbacher, A.; Saake, K.; Winegar, A.; Fogel, R.; Cacchione, J. COVID-19 Pandemic, CLABSI, and CAUTI: The Urgent Need to Refocus on Hardwiring Prevention Efforts. Infect. Control Hosp. Epidemiol. 2021, 19, 1-6. [CrossRef] [PubMed]

19. Wang, L.; Amin, A.K.; Khanna, P.; Aali, A.; Mcgregor, A.; Bassett, P.; Gopal Rao, G. An observational cohort study of bacterial co-infection and implications for empirical antibiotic therapy in patients presenting with COVID-19 to hospitals in North West London. J. Antimicrob. Chemother. 2021, 76, 796-803. [CrossRef] [PubMed]

20. Thelen, J.M.; (Noud) Buenen, A.G.; van Apeldoorn, M.; Wertheim, H.F.; Hermans, M.H.A.; Wever, P.C. Community-acquired bacteraemia in COVID-19 in comparison to influenza A and influenza B: A retrospective cohort study. BMC Infect. Dis. 2021, 21, 199. [CrossRef]

21. Grasselli, G.; Zangrillo, A.; Zanella, A.; Antonelli, M.; Cabrini, L.; Castelli, A.; Cereda, D.; Coluccello, A.; Foti, G.; Fumagalli, R.; et al. Baseline Characteristics and Outcomes of 1591 Patients Infected with SARS-CoV-2 Admitted to ICUs of the Lombardy Region, Italy. JAMA 2020, 323, 1574-1581. [CrossRef] [PubMed] 
22. D’Onofrio, V.; Van Steenkiste, E.; Meersman, A.; Waumans, L.; Cartuyvels, R.; Van Halem, K.; Messiaen, P.; Gyssens, I.C. Differentiating influenza from COVID-19 in patients presenting with suspected sepsis. Eur. J. Clin. Microbiol. Infect. Dis. 2021, 40, 987-995. [CrossRef] [PubMed]

23. Zhou, S.; Yang, Y.; Zhang, X.; Li, Z.; Liu, X.; Hu, C.; Chen, C.; Wang, D.; Peng, Z. Clinical Course of 195 Critically Ill COVID-19 Patients: A Retrospective Multicenter Study. Shock 2020, 54, 644-651. [CrossRef] [PubMed]

24. Haedo, M.; Melendi, S.; Mauri, M.; Ujeda, C.; Leis, R. Usefulness of blood coltures in COVID-19 pneumonia. Medicina 2020, 80, 44-47. [PubMed]

25. Lendorf, M.; Boisen, M.; PL, K.; Lokkegard, E.; Krog, S.; Brandi, L.; Fischer, T. Characteristics and early outcomes of patients hospitalised for COVID-19 in North Zealand, Denmark. Dan. Med. J. 2020, 67, A06200428.

26. Girona-Alarcon, M.; Bobillo-Perez, S.; Sole-Ribalta, A.; Hernandez, L.; Guitart, C.; Suarez, R.; Balaguer, M.; Cambra, F.J.; Jordan, I. The different manifestations of COVID-19 in adults and children: A cohort study in an intensive care unit. BMC Infect. Dis. 2021, 21, 87. [CrossRef]

27. Engsbro, A.L.; Israelsen, S.B.; Pedersen, M.; Tingsgaard, S.; Lisby, G.; Andersen, C.; Benfield, T. Predominance of hospital-acquired bloodstream infection in patients with Covid-19 pneumonia. Infect. Dis. (Auckl.) 2020, 52, 919-922. [CrossRef]

28. Mormeneo Bayo, S.; Palacián Ruíz, M.P.; Moreno Hijazo, M.; Villuendas Usón, M.C. Bacteremia during COVID-19 pandemic in a tertiary hospital in Spain. Enferm. Infecc. Microbiol. Clin. 2021, in press. [CrossRef]

29. Søgaard, K.K.; Baettig, V.; Osthoff, M.; Marsch, S.; Leuzinger, K.; Schweitzer, M.; Meier, J.; Bassetti, S.; Bingisser, R.; Nickel, C.H.; et al. Community-acquired and hospital-acquired respiratory tract infection and bloodstream infection in patients hospitalized with COVID-19 pneumonia. J. Intensive Care 2021, 9, 1-10. [CrossRef]

30. Chen, S.; Zhu, Q.; Xiao, Y.; Wu, C.; Jiang, Z.; Liu, L.; Qu, J. Clinical and etiological analysis of co-infections and secondary infections in COVID-19 patients: An observational study. Clin. Respir. J. 2021, 15, 815-825. [CrossRef]

31. Soriano, M.C.; Vaquero, C.; Ortiz-Fernández, A.; Caballero, A.; Blandino-Ortiz, A.; de Pablo, R. Low incidence of co-infection, but high incidence of ICU-acquired infections in critically ill patients with COVID-19. J. Infect. 2021, 82, e20-e21. [CrossRef] [PubMed]

32. Suarez-de-la-, A.; Falces-romero, I. Original Secondary infections in mechanically ventilated patients with COVID-19: An overlooked matter? Rev. Española Quimioter. 2021, 1-7, 330-336. [CrossRef] [PubMed]

33. Baskaran, V.; Lawrence, H.; Lansbury, L.E.; Webb, K.; Safavi, S.; Zainuddin, N.I.; Huq, T.; Eggleston, C.; Ellis, J.; Thakker, C.; et al. Co-infection in critically ill patients with COVID-19: An observational cohort study from England. J. Med. Microbiol. 2021, 70, 001350. [CrossRef]

34. Lardaro, T.; Wang, A.Z.; Bucca, A.; Croft, A.; Glober, N.; Holt, D.B.; Musey, P.I.; Peterson, K.D.; Trigonis, R.A.; Schaffer, J.T.; et al. Characteristics of COVID-19 patients with bacterial coinfection admitted to the hospital from the emergency department in a large regional healthcare system. J. Med. Virol. 2021, 93, 2883-2889. [CrossRef] [PubMed]

35. Gidaro, A.; Vailati, D.; Gemma, M.; Lugli, F.; Casella, F.; Cogliati, C.; Canelli, A.; Cremonesi, N.; Monolo, D.; Cordio, G.; et al Retrospective survey from vascular access team Lombardy net in COVID-19 era. J. Vasc. Access 2021, in press. [CrossRef] [PubMed]

36. Bonazzetti, C.; Morena, V.; Giacomelli, A.; Oreni, L.; Casalini, G.; Galimberti, L.R.; Bolis, M.; Rimoldi, M.; Ballone, E.; Colombo, R.; et al. Unexpectedly High Frequency of Enterococcal Bloodstream Infections in Coronavirus Disease 2019 Patients Admitted to an Italian ICU: An Observational Study. Crit. Care Med. 2020, 49, E31-E40. [CrossRef]

37. Buehler, P.K.; Zinkernagel, A.S.; Hofmaenner, D.A.; Wendel Garcia, P.D.; Acevedo, C.T.; Gómez-Mejia, A.; Mairpady Shambat, S.; Andreoni, F.; Maibach, M.A.; Bartussek, J.; et al. Bacterial pulmonary superinfections are associated with longer duration of ventilation in critically ill COVID-19 patients. Cell Rep. Med. 2021, 2, 100229. [CrossRef]

38. Adler, H.; Ball, R.; Fisher, M.; Mortimer, K.; Vardhan, M.S. Low rate of bacterial co-infection in patients with COVID-19. Lancet Microbe 2020, 1, e62. [CrossRef]

39. Blazoski, C.; Baram, M.; Hirose, H. Outcomes of extracorporeal membrane oxygenation in acute respiratory distress syndrome due to COVID-19: The lessons learned from the first wave of COVID-19. J. Card. Surg. 2021, 36, 2219-2224. [CrossRef]

40. Rothe, K.; Feihl, S.; Schneider, J.; Wallnöfer, F.; Wurst, M.; Lukas, M.; Treiber, M.; Lahmer, T.; Heim, M.; Dommasch, M.; et al. Rates of bacterial co-infections and antimicrobial use in COVID-19 patients: A retrospective cohort study in light of antibiotic stewardship. Eur. J. Clin. Microbiol. Infect. Dis. 2021, 40, 859-869. [CrossRef]

41. Kumar, G.; Adams, A.; Hererra, M.; Rojas, E.R.; Singh, V.; Sakhuja, A.; Meersman, M.; Dalton, D.; Kethireddy, S.; Nanchal, R.; et al. Predictors and outcomes of healthcare-associated infections in COVID-19 patients. Int. J. Infect. Dis. 2021, 104, $287-292$. [CrossRef]

42. Karruli, A.; Boccia, F.; Gagliardi, M.; Patauner, F.; Ursi, M.P.; Sommese, P.; De Rosa, R.; Murino, P.; Ruocco, G.; Corcione, A.; et al. Multidrug-Resistant Infections and Outcome of Critically Ill Patients with Coronavirus Disease 2019: A Single Center Experience. Microb. Drug Resist. 2021. [CrossRef]

43. Garcia-Vidal, C.; Sanjuan, G.; Moreno-García, E.; Puerta-Alcalde, P.; Garcia-Pouton, N.; Chumbita, M.; Fernandez-Pittol, M.; Pitart, C.; Inciarte, A.; Bodro, M.; et al. Incidence of co-infections and superinfections in hospitalized patients with COVID-19: A retrospective cohort study. Clin. Microbiol. Infect. 2021, 27, 83-88. [CrossRef]

44. Marcus, J.E.; Sams, V.G.; Barsoumian, A.E. Elevated secondary infection rates in patients with coronavirus disease 2019 (COVID19) requiring extracorporeal membrane oxygenation. Infect. Control Hosp. Epidemiol. 2021, 42, 770-777. [CrossRef] 
45. Akagi, E.F.; Sharma, M.; Johnson, L.B.; Szpunar, S.M.; Riederer, K.; Saravolatz, L.D.; Bhargava, A. Clinical features and risk factors for community-onset bloodstream infections among coronavirus disease 2019 (COVID-19) patients. Infect. Control Hosp. Epidemiol. 2021, 42, 899-901. [CrossRef]

46. Wendel Garcia, P.D.; Fumeaux, T.; Guerci, P.; Heuberger, D.M.; Montomoli, J.; Roche-Campo, F.; Schuepbach, R.A.; Hilty, M.P. Prognostic factors associated with mortality risk and disease progression in 639 critically ill patients with COVID-19 in Europe: Initial report of the international RISC-19-ICU prospective observational cohort. EClinicalMedicine 2020, 25, 100449. [CrossRef]

47. Cheng, K.; He, M.; Shu, Q.; Wu, M.; Chen, C.; Xue, Y. Analysis of the risk factors for nosocomial bacterial infection in patients with COVID-19 in a tertiary hospital. Risk Manag. Healthc. Policy 2020, 13, 2593-2599. [CrossRef]

48. Martinez-Guerra, B.A.; Gonzalez-Lara, M.F.; de-Leon-Cividanes, N.A.; Tamez-Torres, K.M.; Roman-Montes, C.M.; Rajme-Lopez, S.; Villalobos-Zapata, G.I.; Lopez-Garcia, N.I.; Martínez-Gamboa, A.; Sifuentes-Osornio, J.; et al. Antimicrobial resistance patterns and antibiotic use during hospital conversion in the COVID-19 pandemic. Antibiotics 2021, 10, 182. [CrossRef]

49. Barry, M.; Althabit, N.; Akkielah, L.; AlMohaya, A.E.; Alotaibi, M.; Alhasani, S.; Aldrees, A.; AlRajhi, A.; AlHiji, A.; Almajid, F.; et al. Clinical characteristics and outcomes of hospitalized COVID-19 patients in a MERS-CoV referral hospital during the peak of the pandemic. Int. J. Infect. Dis. 2021, 106, 43-51. [CrossRef]

50. Giacobbe, D.R.; Battaglini, D.; Ball, L.; Brunetti, I.; Bruzzone, B.; Codda, G.; Crea, F.; De Maria, A.; Dentone, C.; Di Biagio, A.; et al. Bloodstream infections in critically ill patients with COVID-19. Eur. J. Clin. Investig. 2020, 50, 13319. [CrossRef]

51. Zhang, H.; Zhang, Y.; Wu, J.; Li, Y.; Zhou, X.; Li, X.; Chen, H.; Guo, M.; Chen, S.; Sun, F.; et al. Risks and features of secondary infections in severe and critical ill COVID-19 patients. Emerg. Microbes Infect. 2020, 9, 1958-1964. [CrossRef]

52. Ripa, M.; Galli, L.; Poli, A.; Oltolini, C.; Spagnuolo, V.; Mastrangelo, A.; Muccini, C.; Monti, G.; De Luca, G.; Landoni, G.; et al. Secondary infections in patients hospitalized with COVID-19: Incidence and predictive factors. Clin. Microbiol. Infect. 2021, 27, 451-457. [CrossRef]

53. Contou, D.; Claudinon, A.; Pajot, O.; Micaëlo, M.; Longuet Flandre, P.; Dubert, M.; Cally, R.; Logre, E.; Fraissé, M.; Mentec, H.; et al. Bacterial and viral co-infections in patients with severe SARS-CoV-2 pneumonia admitted to a French ICU. Ann. Intensive Care 2020, 10, 119. [CrossRef]

54. Nori, P.; Cowman, K.; Chen, V.; Bartash, R.; Szymczak, W.; Madaline, T.; Punjabi Katiyar, C.; Jain, R.; Aldrich, M.; Weston, G.; et al. Bacterial and fungal coinfections in COVID-19 patients hospitalized during the New York City pandemic surge. Infect. Control Hosp. Epidemiol. 2021, 42, 84-88. [CrossRef]

55. Grasselli, G.; Scaravilli, V.; Mangioni, D.; Scudeller, L.; Alagna, L.; Bartoletti, M.; Bellani, G.; Biagioni, E.; Bonfanti, P.; Bottino, N.; et al. Hospital-acquired infections in critically-ill COVID-19 patients. Chest 2021, 160, 454-465. [CrossRef]

56. Cui, J.; Li, M.; Cui, J.; Wang, J.; Qiang, X.; Liang, Z. The proportion, species distribution and dynamic trends of bloodstream infection cases in a tertiary hospital in China, 2010-2019. Infection 2021, 1-10. [CrossRef]

57. The ProCESS Investigators A Randomized Trial of Protocol-Based Care for Early Septic Shock. N. Engl. J. Med. 2014, 370, 1683-1693. [CrossRef]

58. Vincent, J.L.; Sakr, Y.; Singer, M.; Martin-Loeches, I.; MacHado, F.R.; Marshall, J.C.; Finfer, S.; Pelosi, P.; Brazzi, L.; Aditianingsih, D.; et al. Prevalence and Outcomes of Infection among Patients in Intensive Care Units in 2017. JAMA 2020, 323, $1478-1487$. [CrossRef]

59. Wicky, P.H.; Niedermann, M.S.; Timsit, J.F. Ventilator-associated pneumonia in the era of COVID-19 pandemic: How common and what is the impact? Crit. Care 2021, 25, 153. [CrossRef]

60. Langford, B.J.; So, M.; Raybardhan, S.; Leung, V.; Westwood, D.; MacFadden, D.R.; Soucy, J.P.R.; Daneman, N. Bacterial coinfection and secondary infection in patients with COVID-19: A living rapid review and meta-analysis. Clin. Microbiol. Infect. 2020, 26, 1622-1629. [CrossRef] 